\title{
Treatment with angiotensin II in COVID-19 patients may not be beneficial
}

\author{
Susanne Rysz ${ }^{1,2}$, Francesca Campoccia Jalde ${ }^{2,3}$, Anders Oldner ${ }^{2,3}$, Lars I. Eriksson 2,3, Johan Lundberg ${ }^{4,5}$ and \\ Malin Jonsson Fagerlund ${ }^{2,3^{*}}$ (i)
}

\section{Dear Editor,}

We read with great interest the recent article by Zangrillo et al. regarding infusion of angiotensin II (ANGII) in COVID-19 [1], stating that ANGII vasopressor treatment may be logical in the setting of COVID-19 patients requiring vasopressor support. The authors refer to the ATHOSIII trial as support for the use of ANGII in catecholamine-resistant vasodilatory shock despite the known concern for thrombotic and infectious complications associated with ANGII [2]. In addition, the authors suggest to use ANGII in COVID-19 patients recently exposed to angiotensin-converting enzyme inhibitors. We believe that both these statements raise some concern.

SARS-CoV-1 downregulates ACE2 with a subsequent increase in ANGII levels creating a disruption akin to over activating the renin-angiotensin-aldosterone system (RAAS) [3]. In a recent COVID-19 case series, ANGII levels were markedly elevated and linearly associated with viral load and lung injury [4]. Moreover, in a prepublished report currently under journal review, infusion of ANGII in a porcine model rapidly (within hours) induced a clinical syndrome closely reflecting the one seen in COVID-19 patients, including histological changes in the lungs with severe thickening of the alveolar walls, possible hyaline membranes, and clotting of vessels, as previously reported in the human COVID-19 phenotype [5].

We suggest that much of the pathophysiology in ICU patients with COVID-19 is potentially driven by a loss of the inhibition of the RAAS, causing supranormal concentrations of ANGII [5]. In our opinion, the use of ANGII in COVID-19 patients is therefore at present most questionable. Rather, we propose further evaluation of a plausible contributing mechanism of RAAS behind pathophysiology seen in COVID-19.

\section{Authors' response}

\section{Alberto Zangrillo, Giovanni Landoni, Luigi Beretta, Federica Morselli, Ary Serpa Neto and Rinaldo Bellomo}

We thank Dr. Rysz and colleagues for their correspondence [6].

In response, we note that their concerns about the increased risk of thrombosis and infection with angiotensin II have no statistical substance. In addition, for objectivity, other adverse effects would also have to be

This comment refers to the article available at https://doi.org/10.1186/ s13054-020-02928-0.

* Correspondence: malin.jonsson.fagerlund@ki.se

${ }^{2}$ Function Perioperative Medicine and Intensive Care, Karolinska University Hospital, Stockholm, Sweden

${ }^{3}$ Department of Physiology and Pharmacology, Karolinska Institutet, Stockholm, Sweden

Full list of author information is available at the end of the article similarly considered, such as a $34 \%$ reduction in adverse effects leading to discontinuation compared to placebo, or the $34 \%$ reduction in respiratory adverse events, or the absolute $6.4 \%$ reduction in serious adverse events compared to placebo [7].

The endocytosis of ACE2 following contact with the COVID-19 virus could be decreased by conformational changes in ACE2 secondary to angiotensin II binding to it. In addition, such binding could itself decrease the ability of the virus to bind to the receptor and enter the cell. Such hypothetical interactions, however, remain unmeasured. Moreover, it is not a surprise that angiotensin II levels are higher in patients with greater 
viral load and illness severity. Such high levels can easily represent the response to inflammatory vasodilatation and the body's attempt to restore perfusion pressure.

Finally, the infusion of angiotensin II in the porcine model cited by the correspondents is clearly irrelevant to angiotensin therapy in humans as described in our report [1]. We administered $20 \mathrm{ng} / \mathrm{kg} / \mathrm{min}$ [1], while the investigators escalated to $80 \mathrm{ng} / \mathrm{kg} / \mathrm{min}$ within $60 \mathrm{~min}$ and then all the way to $240 \mathrm{ng} / \mathrm{kg} / \mathrm{min}$. In other animals, the dose was up to $640 \mathrm{ng} / \mathrm{kg} / \mathrm{min}$. At such toxic doses which were 10 to 30 times those administered to our patients, it is no surprise that toxic, even lethal side effects developed.

Until more relevant experiments are performed or clear evidence emerges that angiotensin II infusion is injurious in COVID-19 patients, the data are strong that angiotensin II is a safe and effective vasopressor agent [8] especially in patients with high renin levels [9].

\section{Acknowledgements}

Not applicable

\section{Authors' contributions}

$S R$, JL, and MJF drafted the paper. All authors critically reviewed the manuscript. All authors read and approved the final version of the manuscript.

\section{Funding}

$J$ was supported by the Stockholm Region Clinical Postdoc program and MedTech Labs at Karolinska Institutet.

Availability of data and materials

Not applicable.

Ethics approval and consent to participate

Not applicable.

\section{Consent for publication}

Not applicable.

\section{Competing interests}

The authors declare that they have no competing interests.

\section{Author details}

'Department of Medicine Solna, Karolinska Institutet, Stockholm, Sweden. ${ }^{2}$ Function Perioperative Medicine and Intensive Care, Karolinska University Hospital, Stockholm, Sweden. ${ }^{3}$ Department of Physiology and Pharmacology, Karolinska Institutet, Stockholm, Sweden. ${ }^{4}$ Department of Clinical Neuroscience, Karolinska Institutet, Stockholm, Sweden. ${ }^{5}$ Department of Neuroradiology, Karolinska University Hospital, Stockholm, Sweden.

Received: 8 July 2020 Accepted: 9 August 2020

Published online: 04 September 2020

\section{References}

1. Zangrillo A, Landoni G, Beretta L, Morselli F, Serpa Neto A, Bellomo R, et al. Angiotensin II infusion in COVID-19-associated vasodilatory shock: a case series. Crit Care. 2020;24:227. https://doi.org/10.1186/s13054-020-02928-0.

2. Farina N, Bixby A, Alaniz C, Angiotensin II. Brings more questions than answers. P T. 2018;43:685-7.

3. Gheblawi M, Wang K, Viveiros A, Nguyen Q, Zhong J-C, Turner AJ, et al. Angiotensin-converting enzyme 2: SARS-CoV-2 receptor and regulator of the renin-angiotensin system: celebrating the 20th anniversary of the discovery of ACE2. Circ Res. 2020;126:1456-74.
4. Liu Y, Yang Y, Zhang C, Huang F, Wang F, Yuan J, et al. Clinical and biochemical indexes from 2019-nCoV infected patients linked to viral loads and lung injury. Sci China Life Sci. 2020;63:364-74.

5. Rysz S, Al-Saadi J, Farm M et al. COVID-19 pathophysiology may be driven by a loss of inhibition of the renin-angiotensin-aldosterone system. PREPRI NT (Version 2) available at Research Square. https://doi.org/10.21203/rs.3.rs32494/v2.

6. Rysz S, Campoccia Jalde F, Oldner A, et al. Treatment with angiotensin II in COVID-19 patients may not be beneficial. Crit Care. 2020.

7. Khanna A, English SW, Wang XS, et al. Angiotensin II for the treatment of vasodilatory shock. N Engl J Med. 2017:377:419-30.

8. Bellomo R, Hilton A. The ATHOS-3 trial, angiotensin II and the three musketeers. Crit Care Resusc. 2017;19:3-4.

9. Bellomo R, Forni LG, Busse LW et al. Renin and survival in patients given angiotensin II for catecholamine-resistant vasodilatory shock. Am J Respir Crit Care Med. 2020. Online ahead of print.

\section{Publisher's Note}

Springer Nature remains neutral with regard to jurisdictional claims in published maps and institutional affiliations. 